\title{
Understanding Health Care Professional-Patient Interactions in Multiple Sclerosis: A Systematic Review and Thematic Synthesis
}

\author{
Andrew Soundy ${ }^{1}$, Carolyn Roskell1, Rachel Adams², Tracey Elder ${ }^{1}$, Helen Dawes ${ }^{3}$ \\ ${ }^{1}$ Department of Physiotherapy, School of Sport, Exercise and Rehabilitation Sciences, University of Birmingham, Birmingham, UK \\ ${ }^{2}$ Institute of Applied Health Research, College of Medicine \& Dentistry, University of Birmingham, Birmingham, UK \\ ${ }^{3}$ Department of Sport and Health Sciences, Faculty of Health and Life Sciences, Oxford Brookes University, Oxford, UK \\ Email: ${ }^{\star A}$ A.A.Soundy@bham.ac.uk
}

How to cite this paper: Soundy, A., Roskell, C., Adams, R., Elder, T. and Dawes, H. (2016) Understanding Health Care Professional-Patient Interactions in Multiple Sclerosis: A Systematic Review and Thematic Synthesis. Open Journal of Therapy and Rehabilitation, 4, 187-217. http://dx.doi.org/10.4236/ojtr.2016.44018

Received: October 4, 2016

Accepted: November 4, 2016

Published: November 7, 2016

Copyright $\odot 2016$ by authors and Scientific Research Publishing Inc. This work is licensed under the Creative Commons Attribution International License (CC BY 4.0).

http://creativecommons.org/licenses/by/4.0/

(c) (i) Open Access

\begin{abstract}
Aim: To examine the experiences of health care professional (HCP)-patient interactions in Multiple Sclerosis (MS), identifying factors that can influence these interactions. Methods: A three-stage systematic review and thematic synthesis of qualitative and quantitative research was undertaken. Stage 1: the systematic literature search; Stage 2: methodological appraisal of the qualitative papers; Stage 3: thematic synthesis of all qualitative papers and the integration of quantitative findings into the synthesis. Results: Forty-nine qualitative studies were identified. This included 1014 individuals with MS (244 male, 755 female and 15 unknown) and 106 carers and 86 HCPs. Seventeen quantitative studies were identified which included 7680 (2008 male, 5812 females, and 40 unknown) participants as well as 224 carers. Two themes are discussed: 1) The expectations, experiences and perceptions of interactions with HCPs, and 2) The factors that influenced interactions and relationships. Discussion: There is need for improvement in the content and provision of information to patients with MS from HCPs. Specific strategies are suggested and implications for patients and health care providers are considered.
\end{abstract}

\section{Keywords}

Qualitative, Meta-Synthesis, Interaction, Communication, Therapeutic

Relationships, Health Care Professionals, Neurology, Multiple Sclerosis

\section{Introduction}

Multiple sclerosis (MS) is a disease affecting the brain and spinal cord [1]. It is charac- 
terised by an unpredictable course, but often, over time leads to substantial disability. It is reported to have a considerable impact on an individual's quality of life, ability to continue life roles, to work or undertake leisure activities [2]. Direct medical costs in the US are identified as above $\$ 10$ billion each year [2], and in the UK this has been reported as an average of $£ 8397$ per patient, each 6 months, with costs rising with increasing disability [3]. It affects approximately 2.1 million people in the world [2], representing about $0.3 \%$ of the population in the UK. Data from general practice in the UK has identified that MS has a higher incidence in women than men, with a peak onset between the ages of 40 - 50 years [4].

For individuals with MS, the ability to communicate is central to maintaining their relationships and quality of life [5]. However, impairments often impact on their ability to communicate [6]. This is important as the experience of MS is influenced by how well individuals can participate and interact in their own environment [7]. Thus, health care professional (HCP)-patient interactions and communication are important features that impact on the experience of living with the illness, affecting individuals' sense of identity, feelings and attitudes [8].

The loss and changes that occur following the diagnosis of MS are substantial and can leave individuals vulnerable to poor interactions with HCPs, who, early on in the experiences with the health care sector, have a considerable amount of situational social power [9]. Such power can be exerted over individuals during interactions. Experiences of communication with HCPs can strongly influence patient's generalised hopes and mental well-being [10]. For example, at a basic level, the expression of emotions from the face of HCPs can influence interactions and have a subsequent impact on a patient's general life satisfaction [11]. Further to this, the experience for patients as they progress through the NHS system can be highly challenging. For instance, the moment of receiving a diagnosis has been reported by patients as "poor", "unforgettable" and "evocative" [12].

HCPs have reported that health care services need to be improved for patients with MS [13]. However, they lack understanding of when problems are experienced and why and how these can be improved. In order to understand this need a comprehensive review or policy document is required. Further to this, research [14] has called for the development of better models of care that are founded on provision of appropriate information about the condition (including the different sub-types), as well as effective co-ordination between different health care groups. Research is calling for a different way of conceptualising communication and care for patients, centred on interaction and mutual enterprise rather than the functional delivery of technical information [15]. One way of achieving this could be through the use of qualitative approaches that document experience as against traditional satisfaction surveys [16] [17].

Recently, the use of evidence syntheses of the experiences of patients with neurological conditions [18] [19] [20], including MS [21], have been extremely useful in beginning to identify, and further understanding of, particular concepts that relate to communication and interaction. Using such an approach, focused explicitly on HCP-patient 
interactions, may advance understanding of patients with MS experiences of interactions as part of working towards improved services for this group.

Qualitative syntheses are able to provide a higher level of evidence-based knowledge [22] and in this instance, compared to a traditional systematic review, would create a greater understanding of the positive and negative experiences of HCP-patient communication and the collective factors that can influence the mental well-being of patients with MS. To the best of the author's knowledge, only generalised reviews [23] and one narrative review [24] including 6 articles have been attempted thus far in the literature. This evidence only identified broad needs for individuals around information provision which is hard to translate into clinical practice and does not consider the factors which influence interactions. A qualitative synthesis could be further extended by considering evidence from quantitative studies to triangulate findings, enabling stronger conclusions to be drawn regarding phenomena, as a basis for development of practical guidance for HCPs as well as researchers. Therefore the aims of the review were to consider the views and experiences of HCP-patient interactions within health services for MS.

\section{Materials and Methods}

A "subtle realist" approach to the review [25] [26] was undertaken. Such an approach helped focus the review on identifying the central factors across the included studies. A systematic review and thematic-synthesis were undertaken in 3 phases.

\subsection{Phase 1 Search Strategy}

A systematic search of the literature was conducted [27] by the primary author. The "SPIDER" [28] eligibility criteria directed the approach. The following electronic databases were included from inception until November 2015: PubMed, Medline, CINHAL, and Sports Discus. We also searched two specific websites including www.googlescholar.com and www.sciencedirect.com. Hand searching of included articles and searching of the publication lists of major authors was performed. The following key words were used (Boolean operators added): Multiple Sclerosis OR MS AND interaction OR relationship OR therapeutic relationship OR communication OR patient-provider communication OR patient provider relationship AND experience OR Perception OR Views Or Attitude AND health care professional OR Patient OR Carer AND Qualitative OR Mixed Methods AND Interview OR Observation. Finally we drew on the corresponding author's existing personal library of documents and considered the reference list of included articles.

\subsection{Eligibility Criteria}

Articles were identified by the primary author and included when they satisfied the following eligibility criteria, considered within the domains of the "SPIDER" search tool [28]:

S-Sample. Articles had to include individuals diagnosed with MS. Studies using dif- 
ferent populations or mixed groups of patients were excluded.

PI-Phenomenon of Interest. Articles had to consider the patient's experience of interactions with health care staff or services. Alternatively, studies may have used the experience and views of others that related to this phenomenon (these included views of HCPs, carers, family or friends). Articles were considered where there was direct reference to this in the results section i.e., it was a direct and significant finding of the research.

D-Design. Any type of qualitative design was considered including phenomenology, grounded theory, or ethnography. Quantitative articles were included considering cross-sectional surveys and mixed methods studies. Articles were excluded if they were reflective pieces, reviews, books, theses, case studies or conference proceedings. The reason for this was to ensure the included articles had been peer reviewed, contained in-depth experiences and perceptions and contained a method section. Internet sources were also excluded if not presented in a traditional article form with a methods section that could be critically evaluated.

E-Evaluation. Articles were required to include the following methods of evaluation: surveys, questionnaires, interview, diaries or focus groups. These methods had to state the aim of documented experiences, views, or attitudes from users. Articles had to be published in English.

$R$-Result Type. To be included, articles needed to include quantitative or qualitative results. The data had to document, or illustrate, verbal and/or nonverbal interactions between patients with MS and HCPs.

\subsection{Stage 2 Critical Appraisal and Study Quality Assessment}

Two authors (AS, CR) undertook the critical appraisal assessment. A modified version of the consolidated criteria for reporting qualitative research (COREQ) [29] was used. The modified version had 13 items and was generated due to the lack of sensitivity from some items of the larger 32-item version [20]. This system scores the quality of the methods section of each article across three domains. Domain 1 considers details regarding the research team and reflexivity ( 5 items), domain 2 considers the study design ( 5 items) and domain 3 considers the data analysis undertaken by each study ( 3 items). Articles that scored less than 4/13 were discussed for their inclusion by two authors (AS, CR). This score was selected as representing a methods section that was potentially poor in quality and required further consideration. After this, the following questions were considered: 1) Are the results believable and could they represent trustworthy expressions of the MS sample in question? 2) Were there any areas of methodological weakness that caused the data to be considered untrustworthy? To be included, answers had to be yes for question 1 and no for question 2. No studies were excluded on this basis.

\subsection{Stage 3 Synthesis of the Review}

A thematic synthesis [30] of qualitative research was undertaken to reveal over-arching 
and emerging themes. The synthesis was undertaken in two phases by the primary author. Phase 1 included several stages that enhanced the analysis. Open coding was used initially to establish a framework, an idea web [31] was used then to group themes and sub-themes, this was followed by a tabulation of themes [32], and 3 revisions to the tables in order to reduce, change and focus the analysis was undertaken. This utilises techniques of honouring original meaning by using key and essential terms by using a key word in context method [33] but also transforming the data in common and linked phrases, terms or phenomena [34]. Phase 2 involved the identification of quantitative findings that related to the themes generated in order to refine, critique and support the phase 1 findings. During this phase vote counting [34] and juxtaposing the data [35] were used to provide the reporting of the synthesis. A full audit trail of processes and example stages can be obtained from the primary author. The qualitative synthesis was presented and supplemented by quantitative research findings. Quantitative findings were used to further develop the point or illustrate unique findings and are presented within the themes generated from the qualitative findings.

The synthesis in the results presents themes, sub-themes and codes. In order to restrict results to the most prevalent and detailed themes, at least 5 (5/49, approximately $10 \%)$ qualitative studies had to support the code or sub-theme. Analysis is detailed by giving a fraction and percentage units in brackets. Generally, percentage units should be interpreted as relative to other scores rather than as absolute units and not be considered as representative rather as more or less common. Fuller and more detailed results can be obtained from the primary author.

\section{Results}

\subsection{Output of Studies}

Forty nine qualitative articles were identified [10] [12] [13] [14] [15] [36]-[79]. From these studies a total of 1014 individuals with MS (244 male, 755 female and 15 unknown) and 106 carers and 86 HCPs were included. The aggregated mean age of participants was 48.0 years and aggregated time since diagnosis was 10.7 years. The diagnoses were as follows (unknown $=707$, known $=307$ ); primary progressive $(\mathrm{n}=48 / 307$, $15.6 \%)$, secondary progressive $(n=117 / 307,38.1 \%)$, relapsing remitting $(n=136 / 307$, $44.3 \%$ ), benign ( $n=6 / 307,2.0 \%$ ). The countries that undertook most of the research included the UK $(\mathrm{n}=14 / 49,28.6 \%)$, the USA $(\mathrm{n}=7 / 49,14.3 \%)$, and Sweden $(\mathrm{n}=7 / 49$, $14.3 \%)$. Most frequently, interviews took place in the patients home $(n=17 / 49,34.7 \%)$ and a community or rehabilitation clinic $(n=8 / 49,16.3 \%)$. The most frequent sampling techniques were purposive $(n=32 / 49,65.3 \%)$ and convenience $(n=14 / 49,28.6 \%)$. The most frequent form of data analysis was thematic analysis $(n=18 / 49,36.7 \%)$ and content analysis $(n=6 / 49,12.2 \%)$.

Seventeen quantitative articles were identified (including two mixed method studies identified within the qualitative studies also) [78]-[94]. From these studies, a total of 7680 (2008 male, 5812 females, and 40 unknown) participants were included as well as 224 carers. Across 4233 patients $(n=2868$ missing) the aggregated mean age was 49.7 
years and aggregated time since diagnosis was 11.0 years. The diagnoses were as follows (unknown $=6611$, known $=1069)$; primary progressive $(n=143 / 1069,13.4 \%)$, secondary progressive $(n=386 / 1069,36.1 \%)$, relapsing remitting $(n=532 / 1069,49.8 \%)$, benign $(\mathrm{n}=8 / 1069,0.7 \%)$. Nine studies used interviews in person and the remaining studies used a postal questionnaire. The most common countries conducting this research included: UK $(\mathrm{n}=3)$, Australia $(\mathrm{n}=3)$, Sweden $(\mathrm{n}=2)$, Norway $(\mathrm{n}=2)$ and Italy $(\mathrm{n}=2)$. The search processes are illustrated in the PRISMA [95] diagram see Figure 1.

\subsection{Critical Appraisal}

\subsubsection{Within COREQ Domain and Item Analysis}

The average score for domain 1 was $1.3 \pm 1.3(1.3 / 5,26 \%)$. The lowest scoring items were identification of participant knowledge of the interviewer and their purposes for

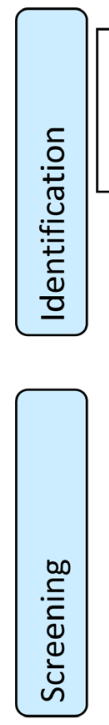

Records identified through database searching $(n=1035)$

Additional records identified through other sources $(n=265)$

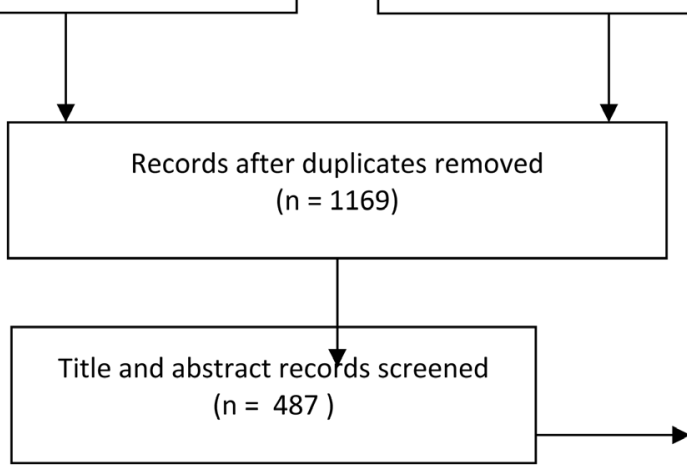

Records excluded $(n=354)$
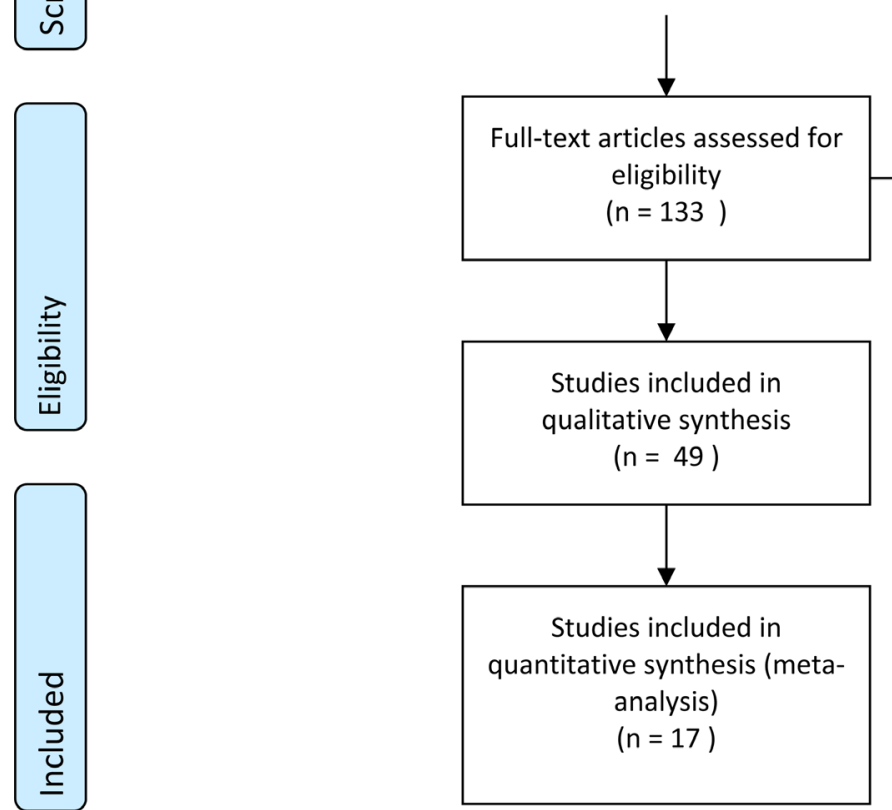

Full-text articles excluded, with reasons $(n=67)$

Diagnosis was incorrect $(n=1)$

Dublicate $(n=14)$

No or too limited focus on services or interactions $(n=42)$

Design of study $(n=10)$

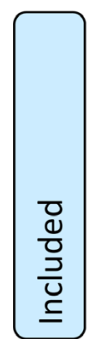

Figure 1. The PRIMSA diagram illustrating the search process. 
conducting research $(6 / 48,12.5 \%$ with identification) and description of the interview characteristics $(4 / 48,8.3 \%)$. The average score for domain 2 was $1.9 \pm 1.5(1.9 / 5,38 \%)$. The lowest scoring items were details regarding reasons for non-participation (15/48, $31.2 \%)$ and identification of data saturation $(14 / 48,29.1 \%)$. The average score of domain 3 was $1.4 \pm 0.9(1.4 / 3,47 \%)$. The lowest scoring domains were identification of a coding tree $(12 / 48,25.0 \%)$ and clarity of minor themes $(10 / 48,20.8 \%)$.

\subsubsection{Between Study Analysis}

A total of $18 / 48(37.5 \%)$ studies scored a total of $3 / 13$ or less. The item that most frequently scored a point for these studies was the "derivation of themes" (13/18, 72.2\%). This suggests that even the lowest scoring studies often have considered or have a rationale for the themes that are generated. The other item that was scored with some consistency was the identification of methodological orientation (4/18, 22.2\%).

\subsection{Synthesis}

The synthesis identified two themes; 1 ) the expectations vs. experiences of HCP-patient interactions, 2) the factors that influenced interactions and relationships. Due to the volume and amount of information generated fuller versions of the results are available from the primary author upon request.

\subsubsection{Theme 1: The Expectations vs. Experiences of HCP-Patient Interactions}

This theme identifies the expectations and subsequent experiences (both good and poor) of HCP-patient interactions. Table 1 provides a full comparison of patient experiences within 5 domains and thus can be used as a summary document in itself. The domains included: 1) timing of information given, 2) needs and experiences considering the MS and symptoms, 3) information-giving related to service provision and needs, 4) needs and experiences of HCPs and 5) reasons why information was identified as valuable. Each domain is separated by wants and expectations vs. good or poor experiences. A summary of the good and poor experiences and expectations of patient's with MS are provided below.

\section{1) Sub-theme: Good experiences of information provision}

There were greater levels of evidence of good experiences of information provision in quantitative articles $(10 / 17,59 \%)$ compared to qualitative articles $(8 / 49,16 \%)$. There appeared to be general satisfaction with information given during HCP-patient interactions $(7 / 17,41 \%)$. Qualitative articles were able to identify reasons why experiences of patients with MS were identified as good or positive. Patients valued the ability of a HCP to; see them quickly, identify problems accurately, acknowledge the limits of science and be able to interact in a responsive and efficient way, as well as arrange follow up meetings $(6 / 49,12 \%)$.

\section{2) Sub-theme: Poor experiences of information provision}

Over half the studies identified negative experiences during HCP-patient interactions; this included slightly higher numbers of qualitative articles $(28 / 49,57 \%)$ than quantitative articles $(9 / 17,53 \%)$. Patients identified experiences of not receiving adequate information 
Table 1. The expectations vs. experiences of information provision in patients with MS.

\begin{tabular}{|c|c|c|}
\hline Area of & $\begin{array}{l}\text { Wants and expectations (support from } \\
\text { qualitative articles }={ }^{\text {a }} \text {, support from }\end{array}$ & $\begin{array}{l}\text { Experiences of informational provisic } \\
\text { (support from qualitative articles }={ }^{a} \text {, }\end{array}$ \\
\hline & quantitative articles $={ }^{b}$, support from & $\begin{array}{l}=\text { support from quantitative articles }=b \\
\text { support from both }={ }^{c} \text { ) }\end{array}$ \\
\hline
\end{tabular}

Support from Research

Expectation:

When was the

information needed

Information before a diagnosis was received or early information

Timing of

information given

Information around the symptoms and how to

Needs and experiences considering the MS and symptoms identify that an attack was occurring ${ }^{c}$

What change in symptoms to expect, the prospects of getting worse

Role of different $\mathrm{HCPs}^{\mathrm{b}}$

\section{Specific information provision}

Poor Experiences of General informational provision

Patients identified not receiving adequate advice or information about what is happening Articles: 3, 4, 12, 15, 19, 23, 36, 48, 49 from doctors ${ }^{\mathrm{c}}$

Patient left with unanswered questions due to; not understanding information at time or not Articles: 1Q, 3Q, 5Q, 12Q, 13Q remembering details ${ }^{\mathrm{a}}$

More information about MS required ${ }^{\mathrm{b}}$

Physical functioning and problems including; walking and balance, bladder and bowel, fatigue, overheating, sexual problems $\mathrm{s}^{\mathrm{b}}$

Information around psychological problems including stress and emotional changes ${ }^{\mathrm{b}}$

Understand the medication they were taking ${ }^{c}$

Information on how to self-manage

End of life care ${ }^{\mathrm{a}}$

Qual: 9/49 (8\%)

Poor Experiences Specific informational provision

Bowel and bladder ${ }^{\mathrm{b}}$ 49

Quant: 4/17 (24\%)

Articles: 3Q, 9Q, 10Q, 16Q
Qual: 9/49 (8\%)

Articles: 3, 4, 12, 15, 19, 23, 36, 48, 49

Quant: 4/17 (24\%)

Articles: 1Q, 3Q, 5Q, $13 \mathrm{Q}$

Expectation: $20,23,24,28,30,36,37,42,45,47,48$,

Identification of action, treatments or

rehabilitation that could be taken ${ }^{c}$

Current research being undertaken ${ }^{\mathrm{b}}$

General information

Expectation:

If free services and agencies were available ${ }^{\mathrm{a}}$

Information giving related to service

what entitlements and financial support the

patient had, further to this where to get money in times of trouble

Poor Experiences of General informational provision

Deficiency of information around services and benefit entitlements ${ }^{\mathrm{a}}$
Qual: 10/49 (20\%)

Articles: 2, 5, 10, 11, 12, 13, 15, 24, 44, 48

Quant: 3/17 (18\%)

Articles: 5Q, 11Q, 12Q

what applications could be made was identified some quantitative study 


\section{Continued}

Needs and experiences of the HCPs
Information about specialists with knowledge about $\mathrm{MS}^{\mathrm{a}}$

\section{Specific information}

MS society, MS support groups, counselling services, and MS specialist nurses ${ }^{\mathrm{b}}$
Poor Experiences.

Qual: $4 / 49(8 \%)$

Articles: 10, 19, 27, 37

Quant: 1/17 (6\%)

Articles: 9Q

Poor Experiences of General informational provision

Lack of information from general practitioners and eye specialists ${ }^{\mathrm{b}}$

Poor experiences of specific informational needs

Patients reported experiences of being given the wrong information around diagnosis ${ }^{\mathrm{a}}$

\section{Expectation:}

Some patients identified that HCPs were not able to diagnosis or identify the experience of MS related symptoms $s^{\mathrm{a}}$

Quant: 1/49 (2\%)

Articles: 9Q

Patients expressed that some HCPs did not know enough leaving patients with unanswered questions ${ }^{\mathrm{a}}$

\section{Poor Experience}

Qual: 15/49 (31\%)

Inappropriate advice regarding treatment and regimes was identified ${ }^{a}$

Articles: 4, 7, 8, 11, 19, 20, 23, 27, 30, $31,35,37,38,46,48$

Information around the end of life care was identified $^{\mathrm{a}}$

Good Experiences.

Good Experiences of general informational needs

Qual: 8/49 (16\%)

Articles: 3, 24, 28, 29, 37, 42, 44, 49

General support for satisfaction with interactions were reported ${ }^{b}$

Quant: 7/17 (41\%)

Good experiences of specific informational needs

Articles: 6Q, 7Q, 8Q, 9Q, 10Q, 13Q, $15 \mathrm{Q}$

Qualitative valued by patients included efficient appointment, accurate diagnosis and identification of problems ${ }^{a}$

Being responsive to questions and acknowledging limits of science and current knowledge $\mathrm{a}^{\mathrm{a}}$

Arranging follow up meetings ${ }^{\mathrm{a}}$

Poor experiences of specific informational needs
Expectation: 


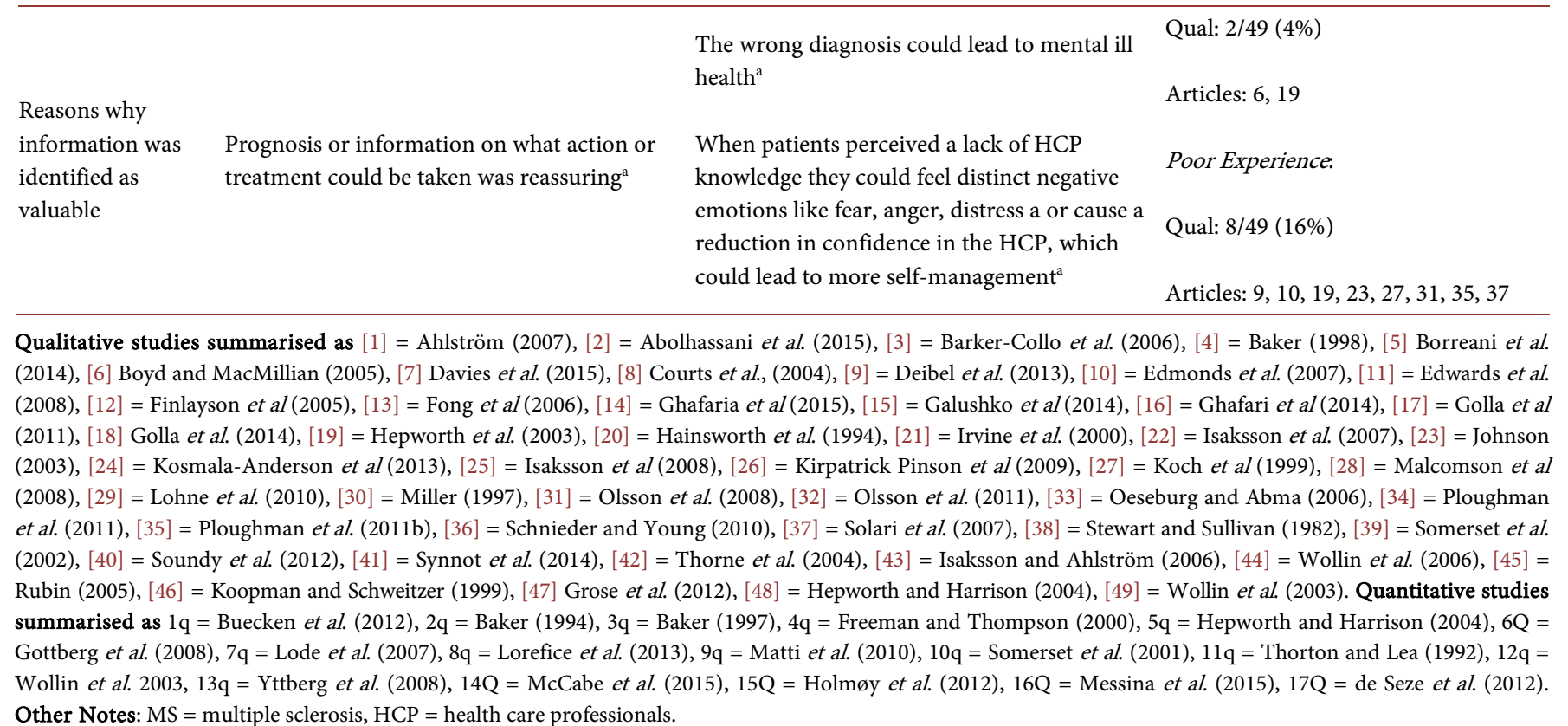

about what is happening from doctors $(10 / 49,20 \%)$. This was supported by a quantitative study and by some HCPs also. Patients suggested that they were left with unanswered questions $(6 / 49,12 \%)$. For example, patients considered some HCPs who were not able to identify symptoms that caused MS as deficient in knowledge $(9 / 49,18 \%)$ or unable to bring the information together that related to the patient. In some cases patients with MS were given the wrong diagnosis and treatment $(7 / 49,14 \%)$ or the HCP could not give a diagnosis of MS or identify the experiences or symptoms that related to MS.

\section{3) Sub-theme: The expectations of patients}

Higher numbers of quantitative $(8 / 17,47 \%)$ studies identified aspects that related to the expectations of patients within interactions compared with the qualitative studies (19/49, 39\%). Patients wanted further information within the following areas; information before a diagnosis was received or early information, the meaning of diagnosis, information around the symptoms and what change in symptoms to expect, or how to identify that an attack was occurring (9/49, 18\%). Quantitative articles (4/17, 24\%) supported these points. Quantitative articles also identified a patient's need for understanding the prospects of getting worse and current research taking place as well as information regarding the role of HCP groups, often physiotherapists (3/17, 18\%). Patients with MS wanted information considering current government regulations around health care system support for MS $(6 / 49,12 \%)$. This included information about; 1$)$ if free services and agencies were available, 2) what entitlements and financial support the patient had and 3) what support was available as the disease progressed, for example, information on particular care services like palliative care. Further to this, where to get money in times of trouble or what applications could be made, was identified in some 
quantitative studies $(3 / 17,18 \%)$. Information regarding treatments $(5 / 49,10 \%)$, selfobtained information and wanting to know if a cure was possible were identified as important concepts that needed to be understood by patients. Three $(3 / 17,18 \%)$ quantitative studies identified the need for patients to have information on the management of symptoms and medication. Additionally, information regarding how to self-manage the condition was important, where more information was considered as having greater value than not understanding enough $(3 / 49,6 \%)$.

\subsubsection{Theme 2: The Factors That Influenced Interactions and Relationships}

This theme considered a variety of bio-psychosocial factors influencing the HCP-patient interaction. Table 2 provides a summary of this theme and support from different articles for this theme.

\section{1) Sub-theme Factors that related to interactions and relationships}

The most prevalent factors included those which were identified as being within a HCP-patient interaction. Nine factors that related to, and impacted on, interactions and relationships with other people were identified and are discussed below.

\section{i) The importance of providing choice for patients}

Some patients identified that they had a lack of choice or felt powerless to change the diagnostic procedures or treatment experience with HCPs (8/49, 16\%). Choice in treatments was identified as important in five quantitative studies $(5 / 17,29 \%)$. This included choice of what information was obtained, opportunity to choose treatments or rehabilitation, and reaching decisions when the patients were too ill to choose or choosing when to disclose information to others. Studies identified patient needs that related to choice including: 1) the need for HCPs to ask questions and make sure patients understood information that was provided, particularly in topics which are more difficult to discuss, as this may limit choice; 2 ) the need to identify who supports (a significant other) the patients within interactions and which HCPs are involved in care, and 3) the ability to consider the patient's own agenda and lists for meetings and interactions and giving the information requested by the patient $(8 / 49,16 \%)$. For example, for some patients being able to talk about the meaning of symptoms and treatment may be important where as for others it may not be. Due to a lack of choice or perceived usefulness of interaction from HCPs to patients, patients could begin to exercise their own choice through taking actions and self-management $(5 / 49,10 \%)$. For example, one study identified that interactions that limited a patients' choice could cause the patient to change HCPs.

Specific factors which were identified as influencing a lack of choice included; 1) interactions that conformed to a clinical agenda, examples of this may include having to experience an interaction which lacks relational (the connection between patient and HCP and how the communication and interaction proceeds, further to the verbal or written provision of disease related information) or inclusive strategies and uses technical language, 2) not being able to leave the hospital grounds as an in-patient, 3) not having other support during encounters from close others, 4) experiencing a devaluing encounter; this was described as including terms not being explained to the patient, a 
Table 2. Considering theme 2 and the factors identified as influencing information and relationships.

Key Findings

$(1=$ evidence where at least 5 qualitative studies (10\%) support the information 2 = unique findings which were

Sub-theme

Code

Included studies support for code identified as "significant" statistically or as clinically meaningful findings; or where prevalence is given a prevalence of $>50 \%$ and when at least $2(15 \%)$ quantitative studies support the finding)

Qual $20 / 49$ or $41 \%$

1) Patients identified interactions that provided little choice, this was worse when they felt they had to confirm to the

The importance of providing choice for patients

Coordination and Continuity of care

family

Sub-theme 2.1 Factors

that related to

interactions and

relationships

Articles: 1, 3, 4, 5, 6, 7, 9, 16, 17, 20, 25, 27, HCPs agenda and when they felt not heard or listened to. $33,34,37,38,39,42,44,45$ There was value for patients when the HCP considered their own agenda and when they could take action and self-management.

2) Variability in the need for information was reported

Quant $8 / 17$ or $47 \%$

Articles: 1Q, 2Q, 3Q, 5Q, 8Q, 13Q, 15Q, 17Q across patients

Qual7/49 or $14.2 \%$

Articles: 5, 10, 15, 17, 23, 27, 47

Quant $3 / 17$ or $18 \%$

Articles: 3Q, 13Q, 15Q

Qual $11 / 49$ or $22 \%$

Articles: 4, 11, 13, 15, 19, 29, 37, 38, 42, 46,

View or support from the 48

\section{Quant $1 / 17$ or $6 \%$}

Articles: 4Q

Qual $12 / 49$ or $24 \%$

The delivery of information and news relating to $M S$

\section{Quant $2 / 17$ or $12 \%$}

Articles: 4Q, 6Q

Judgmental or flippant remarks dismissing the patient and suggesting the patient is misinformed or imagining experiences

Qual 6/49 or $12 \%$

Articles: 8, 11, 32, 38, 42, 43

Qual $8 / 49$ or $16 \%$

Power relations and the perception of patients

that they were not being valued for their thoughts
Articles: $2,8,20,24,27,32,29,42$

Quant $1 / 17$ or $6 \%$

Articles: $6 \mathrm{Q}$

Qual $15 / 49$ or $31 \%$
1) Studies identified a lack of continuity of care, this reflected lack of communication between HCPs and agencies as well as loss of valued HCPs
1) Words or sentences perceived in a negative way, tone of voice which was patronizing, stating that the patient is luckily that it is not worse, or statistics which could be interpreted in negative, and delivery of information in a casual way could have a negative and lasting impact
1) Comments suggesting the patients were lying or imagining symptoms, were perceived as particularly hurtful and negative
1) Experiences that made patients feel worthless and powerless revolved around a paternalistic approach to care, this included being told what to do (without consultation sometimes), belittling remarks, assuming the patient had a low level of knowledge and not taking patient seriously 


\section{Continued}

Insufficient care

experience including

treatment lacking

that affected dignity empathy and sympathy

Articles: 1, 3, 11, 15, 16, 23, 27, 28, 29, 37, 38,

$39,42,43,46$

Quant $7 / 17$ or $41 \%$

Articles: 1Q, 6Q, 7Q, 10Q, 11Q, 13Q, 16Q

Qual $20 / 49$ or $41 \%$

The value of emotional $2,3,4,8,13,14,15,16,17,20,25,28,29,32$, support and being able to $33,37,42,43,45,49$ just listen and provide empathy

Quant $3 / 17$ or $18 \%$

Articles 6Q, 13Q, 15Q

Provision of information,

Qual $8 / 49$ or $16 \%$

trust and empowerment

$16,20,23,26,34,37,41,42$

Qual $10 / 49$ or $20.4 \%$

Articles: 2, 3, 7, 12, 17, 42, 43, 44, 45, 46

Readiness to receive

Sub-theme 2.2 Internal

information

Psychological factors
Quant $6 / 17$ or $35 \%$

Articles: 2Q, 7Q, 11Q, 13Q, 14Q, 16Q
1) Treatment that lacked empathy including experiences which were perceived as impersonal and undignified, that lacked care and compassion ${ }^{\star \star}$

2) This could be more prevalent when this was identified as a need from the patient

1) Emotional support was required, this included listening, giving empathy and sympathy and being respectful**

2) The ability to listen, be sensitive to patients needs was highly valued ${ }^{* *}$. This support helped the patient feel welcomed and valued

3) There was general satisfaction with sympathy and kind treatment from HCP groups

1) Interactions could empower patients when the patient perceived the relationship as a partnership and experienced choice $^{* *}$

1) There were times (notably at diagnosis) when patient's mental well-being meant they were not able to consider information given by HCPs. Distinct emotions and specific adaptation related responses influenced this.

Factors that influenced Qual5/49 or $10.2 \%$

the ability or desire to ask

questions

Articles: 4, 7, 42, 45, 50

Notes: Qualitative studies summarised as [1] = Ahlström (2007), [2] = Abolhassani et al. (2015), [3] = Barker-Collo et al. (2006), [4] = Baker (1998), [5] Borreani et al. (2014), [6] Boyd and MacMillian (2005), [7] Davies et al. (2015), [8] Courts et al., (2004), [9] = Deibel et al. (2013), [10] = Edmonds et al. (2007), [11] = Edwards et al. (2008), [12] = Finlayson et al. (2005), [13] = Fong et al. (2006), [14] = Ghafaria et al. (2015), [15] = Galushko et al. (2014), [16] = Ghafari et al. (2014), [17] = Golla et al. (2011), [18] Golla et al. (2014), [19] = Hepworth et al. (2003), [20] = Hainsworth et al. (1994), [21] = Irvine et al. (2000), [22] = Isaksson et al. (2007), [23] = Johnson (2003), [24] = Kosmala-Anderson et al. (2013), [25] = Isaksson et al. (2008), [26] = Kirpatrick Pinson et al. (2009), [27] = Koch et al. (1999), [28] = Malcomson et al. (2008), [29] = Lohne et al. (2010), [30] = Miller (1997), [31] = Olsson et al. (2008), [32] = Olsson et al. (2011), [33] = Oeseburg and Abma (2006), [34] = Ploughman et al. (2011), [35] = Ploughman et al. (2011b), [36] = Schnieder and Young (2010), [37] = Solari et al. (2007), [38] = Stewart and Sullivan (1982), [39] = Somerset et al. (2002), [40] = Soundy et al. (2012), [41] = Synnot et al. (2014), [42] = Thorne et al. (2004), [43] = Isaksson and Ahlström (2006), [44] = Wollin et al. (2006), [45] = Rubin (2005), [46] = Koopman and Schweitzer (1999), [47] Grose et al. (2012), [48] = Hepworth and Harrison (2004), [49] = Wollin et al. (2003). Quantitative studies summarised as $1 \mathrm{q}=$ Buecken et al. (2012), $2 \mathrm{q}=$ Baker (1994), $3 \mathrm{q}=$ Baker (1997), 4q = Freeman and Thompson (2000), $5 \mathrm{q}=$ Hepworth and Harrison (2004), 6Q = Gottberg et al. (2008), 7q = Lode et al. (2007), 8q = Lorefice et al. (2013), 9q = Matti et al. (2010), 10q = Somerset et al. (2001), 11q = Thorton and Lea (1992), 12q = Wollin et al. 2003, 13q = Yttberg et al. (2008), 14Q = McCabe et al. (2015), 15Q = Holmøy et al. (2012), 16Q = Messina et al. $(2015), 17 \mathrm{Q}=$ de Seze et al. (2012). Quantitative evidence summary: $>25 \%$ prevalence $=$ including information that has a $25 \%$ prevalence rate or substantial evidence, $>50 \%$ prevalence $=$ information on theme is included a critical or majority prevalence rate $\left(>50 \%\right.$ prevalence). ${ }^{*}$ indicates that finding is support by quantitative evidence. Qual $=$ Qualitative studies, Quant $=$ Quantitative Studies.

perception that the HCP was not giving adequate time to the encounter, perceiving that the patient was not heard or listened to, valued or believed from what they said, or being told/prescribed what to do, 5) experiencing increased difficulties at times of transition, or symptom exacerbation.

Further to this there was variability in the perceived value of information within participants responses $(3 / 49,6 \%)$. This was highlighted by quantitative studies $(4 / 17,24 \%)$. Uncertainty around prognosis and change in symptoms could motivate some patients to find out more information. Alternatively it was important to note that some patients were not interested in finding out more about the disease $(2 / 49,4 \%)$ and also that the 
need for information may vary e.g., information around death and dying may not be wanted by some patients.

\section{ii) Coordination and Continuity of care}

A lack of continuity in care or co-ordination of care agencies was identified (5/49, $10 \%)$, although there were good experiences of this in both qualitative and quantitative studies $(2 / 17,12 \%)$. There were different and varied reasons for the poor experiences reported by both patients and HCPs. Patients identified that appointments could only be arranged quite a distance in the future, with long waiting times which could vary by geographical variation in service provision. For example one study stated "the people with MS talked about their frustrations in having to repeat their story with each clinician they met" [77]. HCPs identified that patients wanted one competent HCP who knows the complexities of MS. In addition, it was stated that if the information that the patient wanted to hear was not provided, the patients could change providers. Patients identified that within the journey of MS often there are loss of a specialist who would have other case loads and effectively be withdrawn from the patient's care. This could leave patients with the perception that they were isolated and without support or on their own. It was suggested that poor continuity could be experienced within progressions or transitions in the illness. Continuity in care may be reduced because of the compartmentalization of services or lack of funding for services.

\section{iii) View or support from the family}

During meetings with HCPs, having family members presents was perceived in both a positive and negative way by patients (7/49, 14\%). Positive experiences included the usefulness of having others present in a meeting to remember information, the benefit of being able to share information, the ability to support gathering information and the ability of a relative to acknowledge or accept diagnosis that could aid the patient's adjustment. Negative experiences were reported and included a lack of support from close others, a misunderstanding of the disease by some and a general decrease in social network size. More importantly it also included the spouse leaving or divorce and the patient potentially dying alone. One reason for this may be because the patient perceived close others to treat them differently following disclosure. One quantitative study $(1 / 17$, $6 \%)$ identified that patients who lived alone may increase the requirement for service provision or HCP assistance.

\section{iv) The delivery of information and news relating to MS}

Patients were able to recall negative relational communication, this included; damaging words, sentences, tone of voice and other non-verbal cues like delivery of information in a "casual" way and details about the delivery of information from HCPs and the emotional impact this had on them $(11 / 49,22 \%)$. Patronizing comments were identified as particularly difficult. For example, being told how lucky the patient is that the diagnosis is not worse, or hearing the statistics of what might happen that appear good or positive by an HCP, but may be viewed in a different light by a patient. The provision of unmitigated information from HCPs within diagnosis was identified, for instance one patient remembered the doctor saying "go away and live with it" [54]. 
Another example included not being told directly about the diagnosis, for example being told to read some information around the disease. The outcomes from such experiences could increase fear and frustration in patients and isolate the patient and prevent future contact with services. For example, one study stated that "It was obvious that initial conversations left a lasting negative impression of GPs and/or neurologists and that many participants felt isolated and/or abandoned by the medical team" [61].

Quantitative studies (2/17, 12\%) provided some context for interaction, identifying who provided the majority of interactions and thus who this information may be most suited to. The two most frequently utilized outpatient hospital departments included; neurology and emergency room. The two most frequently accessed professional groups were physicians followed by physiotherapists.

v) Judgmental or flippant remarks dismissing the patient and suggesting the patient is misinformed or imagining experiences

Some patients had experienced remarks and comments that suggested the patient was lying or imagining their experiences $(6 / 49,12 \%)$. This could include instances where the patient had self-diagnosed and the HCPs had stated that it was incorrect, or stated that it was not for the patient to do this. Further to this, some patients described being treated or given information based on their physical appearance and functioning rather than their experiences, thus experiencing a form of discrimination. The views of patients could contrast the views of some HCPs. For example, the provision of "realistic" information from HCPs could be difficult for some patients to accept. For instance, a GP who considers a patient with what he termed as a "mild" form of MS and with this diagnosis then suggests that the patient should keep working, despite the patient wanting to stop.

vi) Power relations and the perception of patients that they were not being valued for their thoughts

Patients identified experiences that made them feel weak, powerless often within a paternalistic approach to care $(6 / 49,12 \%)$. Examples of this included dismissing or trivializing the patient's experience, belittling or making the patient feel like a burden on society, not taking the patient seriously, withholding information or assuming that the patient had a low level of knowledge and being told what to do or what was needed without consultation. For example, one study stated "Believing that important information had been withheld was particularly troublesome to the participants in their quest to learn about their illness and in their efforts to take control over their illness" [72]. The result of such interaction could make the patient feel depressed and desperate.

vii) Insufficient care experience including treatment lacking empathy and sympathy that affected dignity

Patients identified experiences of insufficient care and dissatisfaction with services (9/49, 18\%). Dissatisfaction was most often generated from patients perceiving that the HCP-patient interaction was perceived to be depersonalised way, where little interest was shown towards the patients' situation and circumstance. The experience was often insufficient compared to their expectations of the interaction before hand. Patients used 
words to describe being treated like an "object" or "piece of meat" during care. For example, one patient stated, "I did feel like I was just another patient. It was very impersonal especially since it was such a big deal to me and seemed pretty routine to them" [38]. The experience of such treatment was associated with isolation and loss of dignity. Particular problems were identified as a lack of the following aspects; 1) care, compassion or sensitivity, empathy this was supported by quantitative studies where care was wanted but not received, 2) kind treatment, 3) lack of assistance whilst as an inpatient, 4) too little time for interactions within appointments or an inability to listen or give understanding. According to quantitative studies a problem could occur if this type of support was wanted and not received $(2 / 17,12 \%)$. Some studies identified dissatisfaction with the availability of psychosocial and emotional support $(2 / 17,12 \%)$.

viii) The value of emotional support and being able to just listen and provide empathy

Patients expected comfort and emotional support (20/49, 41\%); this type of support was identified as being more important in patients who were isolated or older. Three quantitative studies $(3 / 17,18 \%)$ identified that there appeared to be general satisfaction with sympathy and kind treatment received from HCPs. Patients highly valued the time that HCPs gave for listening to their experiences and problems in order to validate them $(12 / 49,24 \%)$. Specific qualities during interaction that were valued included being sensitive to the individual's emotional needs, being taken seriously and feeling respected by the HCP $(8 / 49,16 \%)$. For example one patient stated, "One day when I was crying, a nurse held my hand for a few minutes and stayed with me. She listened to me, I needed sympathy, empathy, and reassurance; she gave all these things to me" [50]. HCPs highlighted the value of this form of support.

Particular interactional approaches or skills could enhance this type of support needs. Such documented by patients as valuable included; sympathy, listening or active listening, telling the patient they are not alone and are supported in the process, confirming the patients actions and choices or decisions made, providing the patient with hope, and being respectful. The value of receiving emotional support included feeling welcomed and valued, gaining encouragement, as well as gaining a sense of dignity and hope. Where patients experienced emotional support during interaction with HCPS they reported feeling encouraged, valued and respected. This helped them to feel more hopeful and enhanced their ability to make decisions.

\section{ix) Provision of information, trust and empowerment}

The provision of information and experiences of interactions was able to empower patients or disempower them. Patients felt empowered when they perceived a partnership with a HCP who acknowledged and valued the patient's experience and choice $(6 / 49,12 \%)$. This perception helped patients feel they could express feelings or ask questions. It was also important for patients to feel supported, to trust the HCPs and to receive tailored and accurate information that was direct and understandable. Patients felt disempowered when they perceived themselves to be dependent on the information and advice from the HCP or when HCPs used technical terms or medical jargon with- 
out explaining it. For example one study stated that "Comments such as 'it's a mystery to me' or 'you know more about this than I do' magnified the participants' sense of being alone in managing their disease" [72].

2) Sub-theme 2.2 Internal Psychological factors

Studies identified two internal psychological factors that influenced the HCP-patient interaction.

\section{i) Readiness to receive information}

Patients varied in their own readiness to receive information. A frequently cited reason for this was the mental well-being of the patient $(8 / 49,16 \%)$. Notably emotional or adjustment related responses like denial, fear, anger or depression were reported to prevent the patient being ready to receive information (7/49, 14\%). Fear and worry were increased at certain times, for instance, during the experience of unknown or undiagnosed symptoms, whilst waiting for test results and when worrying about the outcome of test results. Such responses reduced the patient's ability to assimilate information. Interestingly, one quantitative study identified that those more interested in the "uncertainty" surrounding their symptoms and MS, for instance an unknown future, may more actively seek information.

The mental well-being of the patient and ability to receive information varied because of several factors. The factors included; 1) the symptoms experienced, previous experience of symptoms, 2) values and views of the meaning of symptoms in the patient's life, 3) the topic of information being covered within the HCP-patient interaction, for instance, end of life care, or how optimistic or pessimistic the interaction with the HCP had been perceived, 4) the topic within the HCP-patient interaction was of a sensitive nature, or difficult area, not understood well by the HCP, and 5) if information was perceived in a negative way. In addition to this, quantitative studies identified that patients may not know what questions to ask, could be too intimidated, or feel too ignorant about MS to ask. Demographic factors also influenced the ability to receive information, for example, quantitative studies $(3 / 17,18 \%)$ found variation by gender (women had a greater need for emotional support) and age (younger age groups 18 - 39 years wanted more information than older age groups $>40$ years).

ii) Factors that influenced the ability or desire to ask questions

Some patients did not want to ask the HCPs questions or weren't able to ask immediately/expressed hesitation in asking questions to HCPs $(5 / 49,10 \%)$. A variety of reasons were given including; 1) the limited value of asking a question, due to a perception of the HCPs lack of knowledge on the topic (HCPs could be less willing to share information in case it was wrong), 2) not knowing what questions to ask because of a personal lack of understanding about MS, 3) several internal reasons were suggested such as the question not perceived as serious enough to bring up, that acceptance of what had happened by the patient wasn't possible, or that the patient was currently managing so the need to ask a question was less, 4) others didn't want to "bother" the HCPs with their situation and 5) others could be embarrassed about the topic of conversation. Despite this, a worsening of symptoms could prompt patients to return to a HCP for 
further advice. Some patients who did not understand the symptoms of MS or the prognosis of the illness felt more uncertain, fearful, worried or disempowered about what could happen. This was identified by some patients as being associated with the experiences of subsequent depression.

\section{Discussion}

The current review provides a comprehensive overview of the published knowledge considering HCP-patient interactions associated with the care of people with MS. The critical appraisal of included studies identified limitations within the existing literature; these included articles that frequently did not: identify theoretical saturation or give credence to minor themes or provide an audit trail of the analysis. Despite this, most studies had formulated a rationale and provided consideration and justification of the results presented. Thus despite some aspects of methods often missing detail, the results provided by each study were justified with consideration from previous research. The lack of detail regarding minor themes and the failure to discuss whether or not theoretical saturation was achieved provided a rationale for the need and value of this review.

The findings from this review identify the content of HCP-patient interactions as well as detailing factors that influence how patients valued their interactive experience. Quantitative data indicated that the majority of patients were satisfied with their experiences of interactions within health care contexts and rehabilitation. However, it is important to note that Satisfaction surveys are often associated with poor psychometric testing [16] and can be influenced by factors other than the care experienced for instance, by a general reluctance to be negative about care or a perception that the provider has a pressurised or constrained care environment [17]. Thus whilst patients may be satisfied with experiences of care, it doesn't necessarily mean that bad experiences don't occur. In order to be able to respond to the variability of patients' interactional needs, HCPs need to understand what information patients with MS require and what factors can influence HCP-patient interaction.

\subsection{Referential Health Literacy and Information Needs}

Health literacy models for HCPs could be used to improve the HCP-patient interaction [96]. Patients whose health literacy remains poor may as a result be left feeling uninformed, overwhelmed and unable to understand the condition or its impact on their health [96]. Indeed, those who are better informed are more likely to take part in the decision-making process [97]. In the current study, patients highlighted the importance of information, indicating that more information was better than not enough. HCPs, therefore, must be fully equipped to provide this information. In order to be active in shared decision-making, patients first need to be informed of their condition and treatment options [98]. Provision of the correct information can have an empowering effect on patients, aids decision-making and can be essential in the management of the condition [99]. An example of information provision could include a HCP supporting 
the patient with job retention and helping to address their personal problems that are experienced within the work setting [100].

\subsection{Relational and Interactional Factors Which Influence the Patient}

The identification by patients in the current studies of poor information provision within the HCP-patient interaction may stem from "paternalistic" or "task orientated" care [101]. The results here identified evidence of paternalistic care, this included interactions directed by the HCP's agenda or that were medicalised and using terminology that was not explained. Several relational components of the HCP-patient interaction are valued by patients, these include: understanding the patients condition, the patient as a person and being able to listen to and legitimise that the patient's experiences [102]. Current evidence from this review has suggested interactions with patients who have MS lack characteristics that promote the development of therapeutic relations. Receiving task orientated care resulted in poorer emotional well-being and increased dependency during encounters with HCPs. HCPs need to become aware of the emotional impact and acknowledge relational aspects of care [24].

What patients most need from their interactions with HCPs is empathy and to be listened to, and to feel valued for who they are [103] [104]. The current results identified that HCP-patient interactions lacked the basic components needed for an effective therapeutic relationship, where a trusting and safe space is created between practitioner and patient. This is considered central to patient-centred care [105] and needed in order increase self-determination in patients [106]. Good person-centred relationships require that both practitioner and patient know each other as a "person" first before their functional role, founded on empathic engagement [107]. Indeed, HCPs may benefit from further training in how to develop more effective therapeutic relationships that support greater patient participation within a patient-centred model of care. This could focus on developing active listening skills and reflective clarification so that the patient may experience empathy, feeling heard and understood [108].

The current results identified that interactions could also be influenced by lack of continuity with, and loss of trusted or supportive HCPs. In order to enhance trust, patients need to have confidence in the knowledge of the HCP and perceive that the HCP encourages open communication, is willing to work in a team and treat the patient with respect [109]. When a patient forms a trusting relationship they are more willing to disclose information and ask questions necessary for patient empowerment [98]. However, trust can also promote a passive encounter due to an overreliance of the HCP's opinion [98].

\subsection{The Importance of Choice and Shared Decisions}

Contemporary research identifies a need for HCPs to listen to and integrate patient preferences during the HCP-patient interaction. Allowing and promoting patient preferences will help promote a better interaction and shared decision-making [110] [111], even if the patient doesn't make the final decision for the care or rehabilitation [112]. A 
central aspect of patient-centred care is the involvement of patients in decisions. Development of autonomy-supportive interactions [113] [114] and shared decisionmaking [115] are required for HCP-patient interactions. The current review demonstrates that patients with MS are given limited opportunity and choice for decisions about involvement in their care.

Shared decision-making requires a non-confrontational approach which encourages empathetic understanding of the choices and goals identified by patients [103]. Failure to adopt a shared decision-making approach can limit the patient's ability to selfmanage their condition. For patients with MS, a collaborative self-management plan is needed, one which maximises the patient's experience, health literacy and abilities to make decisions [116]. Patients who are more willing and able to manage their condition report better and fairer care experiences (activated) from HCP-patient interactions as well as better health outcomes compared to those who do no report better or fairer experiences (unactivated) [117]. However, it should be acknowledged that there is some recognition that paternalistic care initially, near diagnosis or when transferring a patient to a new environment, might actually aid autonomy [118]. Further consideration and guidance is needed on how HCP-patient interaction can be tailored to accommodate a transition in care, and a change in symptoms, or the situation of a patient.

\subsection{Barriers to Choice and Communication}

The HCP and the patient can create barriers to choice and communication during the HCP-patient interaction. Understanding these is central for developing better patientcentred care. Barriers created by the HCP include: 1) physicians incorrectly perceive that they practice in a patient-centred care, or do not see the role of support self-management as important [119], 2) Feeling limited by the time allowed with patients [119] and 3) use of technical language [98]. Barriers created by the patient include: i) fear of making the wrong decision and/or wanting the HCP to decide [98], ii) belief that they should take a "normal" passive role [98]. Patients worry about being labelled a "problem patient" if they deviate from the expected role, being a "good" patient could be associated with benefits of having more support from the HCP [98]. Preferences for this role can change over time [110], vary by age, culture and gender [120], iii) particular patient perceptions of their $\mathrm{HCP}$ can prevent interaction, these include; patients perceiving physicians to be too busy, hurried during an interaction, having too high a workload, or if they appear to be authoritarian or dismissive [98]. Finally, iv) changes in symptoms, exacerbations or psychological readiness to receive information can have a negative impact on the HCP-patient interaction. Both poor health and cognitive impairment are consistent factors that impact on the HCP-patient interaction [98].

Shock or negative emotional reactions have been reported to impair patients' ability to receive information [20], as well as alternative specific states of mental health, for instance depression [121] or anxiety [122]. Lack of a supportive network (significant others including family and friends) being present within HCP-patients could also impact the patient's ability to adjust to the diagnosis and take in and consider the information 
provided. Patients may also be inhibited by the belief that their questions are not important enough for the HCP to consider [123], that the doctor "knows best", or, that the topics were either too sensitive or too embarrassing in nature [98]. Patients may perceive limited value in asking a question if they believe HCPS' to be ill-informed. In contrast, several relational aspects of the HCP-patient interaction, focused on the unprofessional delivery of information (e.g., use of a casual or patronising manner, dismissing the patient's experience, or implying the patient's problems were psychological), influencing the patients' willingness to ask questions. Other demographic factors that can impact on the HCP-patient interaction include, the age group (older adults can be more accepting of paternalistic care), ethnic background (for example a greater power imbalance was identified by African American men), level of education and differences between the demographics of the interviewer and interviewee [98]. Finally, the settings where the interactions take place, e.g. a lack of privacy or too much noise, can inhibit interaction and patient engagement [98].

\subsection{Clinical Implications}

In order to promote the best care for patients with MS and according to the perception of patients' with MS good HCP-patient interaction should be: responsive, informative within the limits of science, able to identify symptoms and problems, able to arrange follow up care and be supportive. In order to be responsive (see Table 1), HCPs need to understand the common information requirements of patients, they also need be aware of the variation in readiness to ask questions and varying needs of patients. Information giving should be tailored by the HCP to the patient's needs and readiness, doing this will help meet the needs of patients. But to enhance the HCP-patient interaction further other considerations are required and detailed below.

Patients identified that the provision of choice within the HCP-patient interaction was important, supporting patients' needs for HCPs to be more patient-centred. Their responses focused on: what MS-related information HCPs provided, the treatment options presented, the presence of close others in meetings, other decisions and actions taken around care, and disclosure of information to others. It may be that certain HCP groups take on particular features of decision-making, for instance nurses, may be regarded by patients as tending to provide better relational care, they therefore may be best placed to take the lead role in the shared decision-making process, and use their skills to inform other stakeholders, like doctors, of the decisions made [98]. Further research is required to consider this.

Listening and the provision of empathy are essential within interactions. Further training as to how HCPs can develop such skills would enhance effective therapeutic relationships.

Negative HCP-patient interactions have an over reliance on technical wording and the style of delivery. Where possible HCPs should avoid a style that doesn't allow patient input that assumes a certain level of patient knowledge or is dismissive of a patient's concerns. When technical information is delivered it is important that HCPs 
check the patient's understanding of that information.

The ability of HCPs to consider the patient's psychological adaptation to MS could be enhanced by considering and assessing three psychological constructs expressed by patients with MS. The first two constructs include; 1) acknowledgement of one's present and personally defined situation in relation to how MS has impacted on their life and 2) hope in possibility for improving this situation. The final construct includes first realising the choices they have and second acting upon those choices so that they can positively adapt and integrate the changes experienced directly related to MS they. Please see [26] for a conceptual definition of these constructs. Both hope and acknowledgement can be assessed through the use of simple easy to use tools which can assess this quickly e.g. the Hope and Adaptation Scale [124]. Maladaptive responses can then be identified and suitably supported. HCPs can also consider if the patient is able to recognise the different choices that are possible and whether they feel able to act on those choices [26].

Training needs for HCPs have been identified here for techniques and strategies that can support better quality and more patient-centred interactions with HCPs. For instance rehabilitation counselling or training in particular techniques like motivational interviewing or autonomy support (interactions that are able to enhance intrinsic motivation by providing choice, limiting pressure, identifying meaningful aspects of the patients life by listening and creating mutual goals). To support this, clinicians can access and utilise brief guides enhancing autonomy supportive interactions [113] [115].

HCPs must be aware of the impact of relational aspects of communication on the patient's perception of enablement during the HCP-patient interaction. Aspects that influence this include agreements with patients or patient approval, being able to legitimise patients' concerns and the use of humour or laughter [125]. Additionally, HCPs must consider the impact of non verbal communication, in particular hand gestures and facial expressions can have a positive impact on the patients' perception of HCPpatient interview quality [126].

\subsection{Limitations}

The phenomena of focus and the data collection methods for each study varied and some studies only presented small parts of the results, thus the results should not be used to represent the prevalence of poor interactions, but rather they should be considered for relative prevalence against other concepts and be used as data that illustrates how and why interactions can go wrong and what factors can impact on this. The analysis was undertaken by the primary author so may have been biased towards the researcher's previous experience and knowledge. There was limited information from the included studies on the sub-types of MS, thus applicability of these findings to different types of MS must be considered with caution. Data from HCPs and carers is under-represented here and further consideration of the experiences of these stakeholders is required. Limited detail on non-verbal interactions is considered. Generalisability of findings and application to different geographical locations must be considered with 
some caution. All except 3 articles were published after the year 2000, this is a key date for the use of patient-centred care by HCPs within the UK e.g., [127]. Thus, the evaluation of experiences should reflect modern clinical experiences of care.

\subsection{Conclusion}

There is a danger that paternalistic interactive styles taken by HCPs, and within workplace cultures, prevent patients from taking an active role within the HCP-patient interaction creating poor experiences of care. Further to this, the HCP-patient interaction is vulnerable to several psychosocial and interactional factors that often can be improved, resulting in better care experiences and likely improved health outcomes. Further work exploring the development of effective and patient-centred therapeutic relationships in patients with MS is needed. This may help to identify HCP's training needs, enabling them to deliver more effective and mutually-satisfying interactions with people with MS.

\section{Acknowledgements}

The Multiple Sclerosis Society UK for supporting this research.

\section{Contributors}

The main analysis was undertaken by the primary author. The analysis was critiqued by other authors. All authors contributed to the manuscript write up and drafting.

\section{Declaration of Interest}

The Multiple Sclerosis Society UK (award reference 31) for providing funding for this research to be undertaken. No other declarations are made.

\section{References}

[1] Lubin, F.D., Reingold, S.C., Cohen, J.A., Cutter, G.R., Sørensen, P.S., et al. (2014) Defining the Clinical Course of Multiple Sclerosis: The 2013 Revision. Neurology, 83, 278-286. http://dx.doi.org/10.1212/WNL.0000000000000560

[2] Zwibel, H.L. and Smrtka, J. (2011) Improving Quality of Life in Multiple Sclerosis: An Unmet Need. The American Journal of Managed Care, 17, S139-S145.

[3] McCrone, P., Heslin, M., Knapp, M., Bull, P. and Thompson, A. (2008) Multiple Sclerosis in the UK Service Use, Costs, Quality of Life and Disability. Phamacoeconomics, 26, 847860. http://dx.doi.org/10.2165/00019053-200826100-00005

[4] Mackenzie, I.S., Morant, S.V., Bloomfield, G.A., MacDonald, T.M. and O'Riordan, J.I. (2013) Changing Face of Multiple Sclerosis in the United Kingdom 1990-2010. An Incidence and Prevalence Study. Journal of Neurology, Neurosurgery \& Psychiatry, 84, e2. http://dx.doi.org/10.1136/jnnp-2013-306573.27

[5] The Multiple Sclerosis Trust (2011) Multiple Sclerosis Information for Health and Social Care Professionals. Multiple Sclerosis Trust, London.

[6] Duranovic, M., Salihovic, N., Ibrahimagic, A. and Toromanovic, N. (2011) Characteristics of Voice in Individuals with Multiple Sclerosis. Materia Socio Medica, 23, 23-27. 
[7] World Health Organization (2001) International Classification of Functioning, Disability and Health: ICF. World Health Organization, Geneve.

[8] Kagan, A., Simmons, N., Rowland, A., Huijbregts, M., Shumway, E., McEwen, S., Threats, T. and Sharp, S. (2008) Counting What Counts: A Framework for Capturing Real-Life Outcomes of Aphasia Intervention. Aphasiology, 22, 258-280.

http://dx.doi.org/10.1080/02687030701282595

[9] Petkanopoulou, K., Willis, G.B. and Rodríguez-Bailón, R. (2012) Controlling Others and Controlling Oneself: Social Power and Emotion Suppression. Revista de Psicología Social: International Journal of Social Psychology, 27, 305-316.

[10] Soundy, A., Benson, J., Dawes, H., Smith, B., Collett, J., and Meany, A. (2012) Understanding Hope in Patients with Multiple Sclerosis. Physiotherapy, 98, 349-355.

http://dx.doi.org/10.1016/j.physio.2011.05.003

[11] Sanchez, A. and Vazquez, C. (2014) Looking at the Eyes of Happiness: Positive Emotions Mediate the Influence of Life Satisfaction on Attention to Happy Faces. The Journal of Positive Psychology, 9, 435-448. http://dx.doi.org/10.1080/17439760.2014.910827

[12] Solari, A., Acquarone, N., Pucci, E., Marrosu, M.G., Trojano, M., Borreani, C. and Uccelli, M.M. (2007) Communicating the Diagnosis of Multiple Sclerosis a Qualitative Study. Multiple Sclerosis, 13, 763-769. http://dx.doi.org/10.1177/1352458506074689

[13] Golla, H., Galushko, M., Pfaff, H. and Voltz, R. (2011) Unmet Needs of Severely Affected Multiple Sclerosis Patients: The Health Professionals' View. Palliative Medicine, 26, 139151. http://dx.doi.org/10.1177/0269216311401465

[14] Edmonds, P., Vivat, B., Burman, R., Silber, E. and Higginson, I.J. (2007) "Fighting for Everything": Service Experiences of People Severely Affected by Multiple Sclerosis. Multiple Sclerosis, 13, 660-667. http://dx.doi.org/10.1177/1352458506071789

[15] Oeseburg, B. and Abma, T.A. (2006) Care as a Mutual Endeavour: Experiences of a Multiple Sclerosis Patient and Her Healthcare Professionals. Medicine, Health Care and Philosophy, 9, 349-357. http://dx.doi.org/10.1007/s11019-006-0003-6

[16] Sitza, A. (1999) How Valid and Reliable Are Patient Satisfaction Data? An Analysis of 195 Studies. International Journal for Quality in Health Care, 11, 319-328.

http://dx.doi.org/10.1093/intqhc/11.4.319

[17] Canadian Foundation for Health Care Improvement (2013) Myth: High Patient Satisfaction Means High-Quality Care. Journal of Health Services Research and Policy, 18, 255-256. http://dx.doi.org/10.1177/1355819613501426

[18] Hole, E., Stubbs, B., Roskell, C. and Soundy, A. (2014) The Patient's Experience of the Psychosocial Process That Influences Identity Following Stroke Rehabilaition: A Meta-Ethnography. The Scientific World Journal, 2014, 13 p.

[19] Soundy, A. and Condon, N. (2015) Understand How Mental Well-Being Can Be Maintained within Motor Neurone Disease; a Thematic Synthesis Frontiers in Psychology, 6.

[20] Soundy, A., Roskell, C., Elder, T., Collett, J. and Dawes, H. (2016) The Psychological Processes of Hope Adaptation in Patients with Multiple Sclerosis; a Thematic Synthesis. Open Journal of Therapy and Rehabilitation, 4, 22-47.

[21] Soundy, A., Smith, B., Dawes, H., Pall, H., Gimbrere, K. and Ramsay, J. (2013) Patients Expression of Hope and Illness Narratives in Three Neurological Conditions: A Meta-Ethnography. Health Psychology Review, 7, 177-201. http://dx.doi.org/10.1080/17437199.2011.568856

[22] Souza, A., Kelleher, A., Cooper, R., Cooper, R.A., Iezzonia, L.I. and Collins, D.M. (2010) Multiple Sclerosis and Mobility-Related Assistive Technology: Systematic Review of Litera- 
ture. Journal of Rehabiliation Research and Development, 47, 213-223. http://dx.doi.org/10.1682/JRRD.2009.07.0096

[23] Rieckmann, P., Boyko, A., Centonze, D., Elovaara, I., Giovannoni, G., Havrdová, et al. (2015) Achieving Patient Engagement in Multiple Sclerosis: A Perspective from the Multiple Sclerosis in the 21st Century Steering Group. Multiple Sclerosis and Related Disorders, 4, 202-218. http://dx.doi.org/10.1016/j.msard.2015.02.005

[24] Methley, A.M., Chew-Graham, C., Campbell, S. and Cheraghi-Sohi, S. (2014) Experiences of UK Health-Care Services for People with Multiple Sclerosis: A Systematic Narrative Review. Health Expectations, 18, 1844-1855. http://dx.doi.org/10.1111/hex.12228

[25] Hammersley, M. (1992) What's Wrong with Ethnography? Routledge, London.

[26] Soundy, A. and Elder, T. (2016) Developing and Applying the Theory of Psychological Adjustments Needs in Patients with Multiple Sclerosis. In: Watson, R., Ed., Multiple Sclerosis. Food and Lifestyle in Neurological Autoimmune, Elsevier, New York.

[27] Higgins, J.P.T. and Green, S. (2011) Cochrane Handbook for Systematic Reviews of Interventions Version 5.1.0 [Updated March 2011]. The Cochrane Collaboration.

[28] Cooke, A., Smith, D. and Booth, A. (2012) Beyond PICO: The SPIDER Tool for Qualitative Evidence Synthesis. Qualitative Health Research, 22, 1435-1443. http://dx.doi.org/10.1177/1049732312452938

[29] Tong, A., Sainsbury, P. and Craig, J. (2007) Consolidated Criteria for Reporting Qualitative Research (COREQ): A 32-Item Checklist for Interviews and Focus Groups. International Journal for Quality in Health Care, 19, 349-357. http://dx.doi.org/10.1093/intqhc/mzm042

[30] Thomas, J. and Harden, A. (2008) Methods for the Thematic Synthesis of Qualitative Research in Systematic Reviews. BMC Medical Research Methodology, 8, 45.

http://dx.doi.org/10.1186/1471-2288-8-45

[31] Arai, L., Britten, N., Popay, J., Roberts, H., Petticrew, M., Rodgers, M. and Sowden, A. (2007) Testing Methodological Developments in the Conduct of Narrative Synthesis: A Demonstration Review of Research on the Implementation of Smoke Alarm Interventions. Evidence and Policy, 3, 361-383. http://dx.doi.org/10.1332/174426407781738029

[32] Boeije, H. (2002) A Purposeful Approach to the Constant Comparative Method in the Anlaysis of Interviews. Quality and Quantity, 36, 391-409. http://dx.doi.org/10.1023/A:1020909529486

[33] Bernard, H.R. and Ryan, G.W. (2010) Analysing Qualitative Data Systematic Approaches. Sage, London.

[34] Pope, C., Mays, N. and Popay, J. (2007) Synthesizing Qualitative and Quantitative Health Research: A Guide to Methods. Open University Press, Berkshire.

[35] Noblit, G.W. and Hare, R.D. (1988) Meta-Ethnography: Synthesizing Qualitative Studies. Sage, London. http://dx.doi.org/10.4135/9781412985000

[36] Ahlström, G. (2007) Experiences of Loss and Chronic Sorrow in Persons with Severe Chronic Illness. Journal of Nursing and Healthcare in Chronic Illness, 16, 76-83. http://dx.doi.org/10.1111/j.1365-2702.2006.01580.x

[37] Abolhassani, S., Yazdannik, A., Taleghani, F. and Zamani, A. (2015) Expectations of Multiple Sclerosis Patients and Their Families: A Qualitative Study in Iran. Iran Red Crescent Medical Journal, 17, e18293. http://dx.doi.org/10.5812/ircmj.18293

[38] Barker-Collo, S., Cartwright, C. and Read, J. (2006) Into the Unknown: The Experiences of Individuals Living with Multiple Sclerosis. Journal of Neuroscience Nursing, 38, 435-446. http://dx.doi.org/10.1097/01376517-200612000-00008

[39] Baker, L.M. (1998) Sense Making in Multiple Sclerosis: The Information Needs of People 
during an Actue Exacerbation. Qualitative Health Research, 8, 106-120.

http://dx.doi.org/10.1177/104973239800800108

[40] Borreani, C., Bianchi, E., Pietrolongo, E., Rossi, L., Cilia, S., Giuntoli, M., et al. (2014) Unmet Needs of People with Severe Multiple Sclerosis and Their Carers: Qualitative Findings for a Home-Based Intervention. PLOS One, 9, e109679.

http://dx.doi.org/10.1371/journal.pone.0109679

[41] Boyd, J.R. and MacMillan, L.J. (2005) Experiences of Children and Adolescents Living with Multiple Sclerosis. Journal of Neuroscience Nursing, 37, 334-342.

[42] Davies, F., Edwards, A., Brain, K., Edwards, M., Jones, R., Wallbank, R., Robertson, N.P. and Wood, F. (2015) "You Are Just Left to Get on with It": Qualitative Study of Patient and Carer Experiences of the Transition to Secondary Progressive Multiple Sclerosis. BMJ Open, 5, e007674.

[43] Courts, N.F., Buchanan, E.M. and Werstelin, P.O. (2004) Focus groups: The Lived Experience of Participants with Multiple Sclerosis. Journal of Neuroscience Nursing, 36, 42-47. http://dx.doi.org/10.1097/01376517-200402000-00007

[44] Deibel, F., Edwards, M. and Edwards, A. (2013) Patients', Carers' and Providers' Experiences and Requirements for Support in Self-Management of Multiple Sclerosis: A Qualitative Study. European Journal for Person Centered Healthcare, 1, 457-467. http://dx.doi.org/10.5750/ejpch.v1i2.687

[45] Edwards, R.G., Barlow, J.H. and Turner, A.P. (2008) Experiences of Diagnosis and Treatment among People with Multiple Sclerosis. Journal of Evaluation in Clinical Practice, 14, 460-464. http://dx.doi.org/10.1111/j.1365-2753.2007.00902.x

[46] Finlayson, M., Van Denend, T. and Dal Monte, J. (2005) Older Adults' Perspectives on the Positive and Negative Aspects of Living with Multiple Sclerosis. British Journal of Occupational Therapy, 68, 117-124. http://dx.doi.org/10.1177/030802260506800304

[47] Fong, T., Finlayson, M. and Peacock, N. (2006) The Social Experience of Aging with a Chronic Illness: Perspectices of Older Adults with Multiple Sclerosis. Disability and Rehabilitation, 28, 695-705. http://dx.doi.org/10.1080/09638280500277495

[48] Ghafari, S., Fallahi-Khoshknab, M. and Mohammadi, E. (2015) Patients' Experiences of Adapting to Multiple Sclerosis: A Qualitative Study. Contemporary Nurse, 50, 36-49. http://dx.doi.org/10.1080/10376178.2015.1010252

[49] Galushko, M., Golla, H., Strupp, J., Karbach, U., Kaiser, C., Ernstmann, N., et al. (2014) Unmet Needs of Patients Feeling Serverely Affected by Multiple Sclerosis in Germany: A Qualitative Study. Journal of Palliative Care, 17, 274-281.

[50] Ghafari, S., Fallahi-Khoshknab, M., Norouzi, K. and Mohamadi, E. (2014) Experiences of Hospitalization in Patients with Multiple Sclerosis: A Qualitative Study. Iranian Journal of Nursing and Midwifery Research, 19, 255-261.

[51] Golla, H., Galushko, M., Pfaff, H. and Voltz, R. (2014) Multiple Sclerosis and Palliative Care-Perceptions of Severely Affected Multiple Sclerosis Patients and Their Health Professionals: A Qualitative Study. BMC Palliative Care, 13, 11. http://dx.doi.org/10.1186/1472-684X-13-11

[52] Hepworth, M., Harrison, J.M. and James, N. (2003) Information Needs of People with Multiple Sclerosis and the Implications for Information Provision Based on a National Survey. Aslib Proceedings, 55, 290-303. http://dx.doi.org/10.1108/00012530310498860

[53] Hainsworth, M.A. (1994) Living with Multiple Sclerosis: The Experience of Chronic Sorrow. The Journal of Neuroscience Nursing, 26, 237-240. http://dx.doi.org/10.1097/01376517-199408000-00008 
[54] Irvine, H., Davidson, C., Hoy, K. and Lowe-Strong, A. (2009) Psychosocial Adjustment to Multiple Sclerosis: Exploration of Identity Redefinition. Disability and Rehabilitation, 31, 599-606. http://dx.doi.org/10.1080/09638280802243286

[55] Isaksson, A.-K., Gunnarsson, L.-G. and Ahlström, G. (2007) The Presence and Meaning of Chronic Sorrow in Patients with Multiple Sclerosis. Journal of Nursing and Healthcare in Chronic Illness, 16, 315-324. http://dx.doi.org/10.1111/j.1365-2702.2007.01995.x

[56] Johnson, J. (2003) On Receiving the Diagnosis of Multiple Sclerosis: Managing the Transition. Multiple Sclerosis, 9, 82-88. http://dx.doi.org/10.1191/1352458503ms856oa

[57] Kosmala-Anderson, J. and Wallace, L.M. (2013) A Qualitative Study of the Childbearing Experience of Women Living with Multiple Sclerosis. Disability and Rehabilitation, 35, 976-981. http://dx.doi.org/10.3109/09638288.2012.717581

[58] Isaksson, A.-K. and Ahlström, G. (2008) Managing Chronic Sorrow: Experiences of Patients with Multiple Sclerosis. Journal of Neuroscience Nursing, 40, 180-191. http://dx.doi.org/10.1097/01376517-200806000-00009

[59] Kirkpatrick Pinson, D.M., Ottens, A.J. and Fisher, T.A. (2009) Women Coping Successfully with Multiple Sclerosis and the Precursors of Change. Qualitative Health Research, 19, 181 193. http://dx.doi.org/10.1177/1049732308329465

[60] Koch, T. and Kelly, S. (1999) Understanding What Is Important for Women Who Live with Multiple Sclerosis. The Australian Journal of Holistic Nursing, 6, 14-24.

[61] Malcomson, K.S., Lowe-Strong, A.S. and Dunwoody, L. (2008) What We Can Learn from the Personal Insights of Individuals Living and Coping with Multiple Sclerosis. Disability and Rehabilitation, 2008, 662-674. http://dx.doi.org/10.1080/09638280701400730

[62] Lohne, V., Aasgaard, T., Caspari, S., Slettebo, A. and Naden, D. (2010) The Lonely Battle for Dignity: Individuals Struggling with Multiple Sclerosis. Nursing Ethics, 17, 301-311. http://dx.doi.org/10.1177/0969733010361439

[63] Miller, C.M. (1997) The Lived Experience of Relapsing Multiple Sclerosis: A Phenomenological Study. Journal of Neuroscience Nursing, 29, 294-304.

http://dx.doi.org/10.1097/01376517-199710000-00003

[64] Olsson, M., Lexell, J. and Södergerg, S. (2008) The Meaning of Women's Experiences of Living with Multiple Sclerosis. Health Care for Women International, 29, 416-430. http://dx.doi.org/10.1080/07399330701876646

[65] Olsson, M., Skär, L. and Söderberg, S. (2011) Meanings of Being Received and Met by Others as Experienced by Women with MS. International Journal of Qualitative Studies on Health and Well-Being, 6, 1-8. http://dx.doi.org/10.3402/qhw.v6i1.5769

[66] Ploughman, M., Austin, M.W., Murdoch, M., Kearney, A., Fisk, J.D., Godwin, M. and Stefanelli, M. (2012) Factors Influencing Healthy Aging with Multiple Sclerosis: A Qualitative Study. Disability and Rehabilitation, 34, 26-33. http://dx.doi.org/10.3109/09638288.2011.585212

[67] Ploughman, M. and Austin, M.W. (2011) The Path to Self-Managment: A Qualitative Study Invovling Older People with Multiple Sclerosis. Physiotherapy Canada, 64, 6-17. http://dx.doi.org/10.3138/ptc.2010-42

[68] Schneider, M. and Young, N. (2010) "So This Is My New Life": A Qualitative Examination of Women Living with Multiple Sclerosis and the Coping Strategies They Use When Accessing Physical Activity. Disabiliy Studies Quarterly, 30, 1-13. http://dx.doi.org/10.18061/dsq.v30i3/4.1269

[69] Stewart, D.C. and Sullivan, T.J. (1982) Illness Behavior and the Sick Role in Chronic Disease. Social Science and Medicine, 16, 1397-1404. 
http://dx.doi.org/10.1016/0277-9536(82)90134-4

[70] Somerset, M., Sharp, D. and Campbell, R. (2002) Multiple Sclerosis and Quality of Life: A Qualitative Investigation. Journal of Health Services Research and Policy, 7, 151-159. http://dx.doi.org/10.1258/135581902760082454

[71] Synnot, A., Hill, S., Summers, M. and Taylor, M. (2014) Comparing Face-to-Face and Online Qualitative Research with People with Multiple Sclerosis. Advancing Qualitative Methods, 24, 431-438.

[72] Thorne, S., Con, A., McGuiness, L., McPherson, G. and Harris, S.R. (2004) Health Care Communication Issues in Multiple Sclerosis: An Interpretive Description. Qualitative Health Research, 14, 5-22. http://dx.doi.org/10.1177/1049732303259618

[73] Isaksson, A.-K. and Ahlström, G. (2006) From Symptom to Diagnosis: Illness Experiences of Multiple Sclerosis Patients. Journal of Neuroscience Nursing, 38, 229-237. http://dx.doi.org/10.1097/01376517-200608000-00005

[74] Wollin, J.A., Yates, P.M. and Kristjanson, L.J. (2006) Supportive and Palliative Care Needs Identified by Multiple Sclerosis Patients and Their Families. International Journal of Palliative Nursing, 12, 20-26. http://dx.doi.org/10.12968/ijpn.2006.12.1.20392

[75] Rubin, R. (2005) Communication about Sexual Problems in Male Patients with Multiple Sclerosis. Nursing Standard, 19, 33-37. http://dx.doi.org/10.7748/ns.19.24.33.s54

[76] Koopman, W. and Schweitzer, A. (1999) The Journey to Multiple Sclerosis. Journal of Neuroscience Nursing, 31, 17-26. http://dx.doi.org/10.1097/01376517-199902000-00003

[77] Grose, J., Freeman, J. and Skirton, H. (2012) Value of a Confidant Relationship in Pyschosocial Care of People with Multiple Sclerosis. International Journal of Multiple Sclerosis Care, 14, 115-122.

[78] Hepworth, M. and Harrison, J.M. (2004) A Survey of the Informational Needs of People with Multiple Sclerosis. Health Informatics Journal, 10, 49-69.

http://dx.doi.org/10.1177/1460458204040668

[79] Wollin, J., et al. (2003) What People with Newly Diagnosed MS (and Their Families and Friends) Need to Know. International Journal of Multiple Sclerosis Care, 2, 1-12.

[80] Buecken, R., Galushko, M., Golla, H., Strupp, J., Hahn, M., Ernstmann, N., et al. (2012) Patients Feeling Severely Affected by Multiple Sclerosis: How Do Patients Want to Communicate about End of Life Issues? Patient Education and Counseling, 88, 318-324. http://dx.doi.org/10.1016/j.pec.2012.03.010

[81] Baker, L.M., Montiors and Blunters (1994) Patient Health Information Seeking from a Different Perspective. Bibliotheca Medica Canadiana, 16, 60-63.

[82] Baker, L.M. (1997) Preference for Physicians as Information Providers by Women with Multiple Sclerosis: A Potential Cause for Communication Problems? Journal of Documentation, 53, 251-262. http://dx.doi.org/10.1108/EUM0000000007199

[83] Freeman, J.A. and Thompson, A.J. (2000) Community Services in Multiple Sclerosis: Still a Matter of Change. Journal of Neurology and Neurosurgery Psychiatry, 69, 728-732. http://dx.doi.org/10.1136/jnnp.69.6.728

[84] Gottberg, K., Einarsson, U., Ytterberg, C., Fredrikson, S., von Koch, L. and Holmqvist, L.W. (2008) Use of Health Care Services and Satisfaction with Care in People with Multiple Sclerosis in Stockholm County: A Population-Based Study. Multiple Sclerosis, 14, 962-971. http://dx.doi.org/10.1177/1352458508089688

[85] Lode, K., Larsen, J.P., Bru, E., Klevan, G., Myhr, K.M. and Nyland, H. (2007) Patient Information and Coping Styles in Multiple Sclerosis. Multiple Sclerosis, 13, 792-799. http://dx.doi.org/10.1177/1352458506073482 
[86] Lorefice, L., Mura, G., Coni, G., Fenu, G., Sardu, C., Frau, J., et al. (2013) What Do Multiple Sclerosis Patients and Their Caregivers Perceive as Unmet Needs? BMC Neurology, 13, 177. http://dx.doi.org/10.1186/1471-2377-13-177

[87] Matti, A.I., McCarl, H., Klaer, P., Keane, M.C. and Chen, C.S. (2010) Multiple Sclerosis: Patients' Information Sources and Needs on Disease Symptoms and Management. Patient Preference and Adherence, 4, 157-161. http://dx.doi.org/10.2147/PPA.S10824

[88] Somerset, M., Campbell, R. and Sharp, D.J. (2001) What Do People with MS Want and Expect from Health Care Services? Health Expectations, 4, 29-37. http://dx.doi.org/10.1046/j.1369-6513.2001.00111.x

[89] Thornton, H.B. and Lea, S.J. (1992) An Investigation into Needs of People Living with Multiple Sclerosis and Their Families. Disability, Handicap and Society, 7, 321-338. http://dx.doi.org/10.1080/02674649266780401

[90] Ytterberg, C., Johansson, S., Gottberg, K., Holmqvist, L.W. and von Koch, L. (2008) Perceived Needs and Satisfaction with Care in People with Multiple Sclerosis: A Two-Year Prospective Study. BMC Neurology, 8, 36. http://dx.doi.org/10.1186/1471-2377-8-36

[91] McCabe, M.P., Ebacioni, K.J., McDonald, E. and Melton, L. (2015) Unmet Education, Psychological and Peer Support Needs of People with Multiple Sclerosis. Journal of Psychosomatic Research, 78, 82-87. http://dx.doi.org/10.1016/j.jpsychores.2014.05.010

[92] Holmøy, T., Hanssen, K.T. and Beiske, A.G. (2012) Patient Satisfaction in Rehabiliation of Patients with Multiple Sclerosis. Tidsskr Nor Legeforen, 132, 523-525.

http://dx.doi.org/10.4045/tidsskr.11.1043

[93] Messina, M.J., Costa, G.D., Rodegher, M., Moiola, L., Colombo, B., Comi, G. and Martinelli, V. (2015) The Communication of Multiple Sclerosis Diagnosis: The Patients' Perspective. Multiple Sclerosis International, 353828, 1-7. http://dx.doi.org/10.1155/2015/353828

[94] de Seze, J., Borgel, F. and Brudon, F. (2012) Patient Perceptions of Multiple Sclerosis and Its Treatment. Patient Preference and Adherence, 6, 263-273.

[95] Moher, D., Liberati, A., Tetzlaff, J. and Altman, D.G., The PRISMA Group (2009) "PRISMA Flow Diagram”. Preferred Reporting Items for Systematic Reviews and Meta-Analysis. Annals of Internal Medicine, 151, 264-269. http://dx.doi.org/10.7326/0003-4819-151-4-200908180-00135

[96] Koh, H.K., Brach, C., Harris, L.M. and Parchman, M.L. (2013) A Proposed "Health Literate Care Model” Would Consitute a Systems Approach to Improving Patients' Engagement in Care. Health Affairs, 32, 357-367. http://dx.doi.org/10.1377/hlthaff.2012.1205

[97] Barry, M.J. and Edgman-Levitan, S. (2012) Shared Decision Making-The Pinnacle of Patient-Centred Care. The New England Journal of Medicine, 368, 780-781. http://dx.doi.org/10.1056/NEJMp1109283

[98] Joseph-Williams, N., Elwyn, G. and Edwards, A. (2014) Knowledge Is Not Power for Patients: A Systematic Review and Thematic Synthesis of Patient-Reported Barriers and Facilitators to Shared Decision Making. Patient Education and Counseling, 94, 291-309. http://dx.doi.org/10.1016/j.pec.2013.10.031

[99] McCabe, M.P. (2012) A Needs Analysis of Australians with MS, M.R. Australia, Editor. MS Research Australia, Melbourne, 1-155.

[100] Doogan, C. and Playford, E.D. (2014) Supporting Work for People with Multiple Sclerosis. Multiple Sclerosis Journal, 20, 646-650. http://dx.doi.org/10.1177/1352458514523499

[101] van der Eijk, M., NiJhuis, F.A. and Bloem, B.R. (2013) Moving from Physician-Centered Care towards Patient-Centered Care for Parkinson's Disease Patients. Parkinsonism and Related Disorders, 19, 923-927. http://dx.doi.org/10.1016/j.parkreldis.2013.04.022 
[102] Hudon, C., Fortin, M., Haggerty, J., Loignon, C., Lambert, M. and Poitras, M.E. (2012) Patient-Centered Care in Chronic Disease Management: A Thematic Analysis of the Literature in Family Medicine. Patient Education and Counseling, 88, 170-176.

http://dx.doi.org/10.1016/j.pec.2012.01.009

[103] Jesus, T.S. and Silva, I.L. (2015) Towards an Evidence Based Patient-Provider Communication in Rehabilitation: Linking Communication Elements to Better Rehabilitation Outcomes. Clinical Rehabilitation, 1-14.

[104] Müssener, U., Svensson, T., Söderberg, E. and Alexanderson, K. (2008) Encouraging Encounters: Sick-Listed Persons' Experience of Interactions with Rehabilitation Professionals. Social Work in Health Care, 46, 71-87. http://dx.doi.org/10.1300/J010v46n02_05

[105] Josephson, I., Woodward-Kron, R., Delany, C. and Hiller, A. (2015) Evaluative Language in Physiotherapy Practice: How Does It Contribute to the Therapeutic Relationship? Social Science and Medicine, 143, 128-136. http://dx.doi.org/10.1016/j.socscimed.2015.08.038

[106] Raeburn, T., Schmied, V., Hungerford, C. and Cleary, M. (2016) Autonomy Support and Recovery Practice at a Psychosocial Clubhouse. Perspectives in Psychiatric Care.

[107] Mead, N. and Bower, P. (2000) Patient-Centredness: A Conceptual Framework and Review of the Empirical Literature. Social Science and Medicine, 51, 1087-1110. http://dx.doi.org/10.1016/S0277-9536(00)00098-8

[108] McLeod, J. and McLeod, J. (2011) Counselling Skills. A Practical Guide for Counsellors and Helping Professionals. 2nd Edition, Open University Press, Maidenhead.

[109] Boquiren, V.M., Hack, T.F., Beaver, K. and Williamson, S. (2015) What Do Measures of Patient Satisfaction with the Doctor Tell Us? Patient Education and Counselling, 98, 14651473. http://dx.doi.org/10.1016/j.pec.2015.05.020

[110] Chewning, B., Byland, C.L., Shah, B., Arora, N.K., Gueguen, J.A. and Makoul, G. (2012) Patient Preference for Shared Decisions: A Systematic Review. Patient Education and Counseling, 86, 9-18. http://dx.doi.org/10.1016/j.pec.2011.02.004

[111] Department of Health (2012) Liberating the NHS: No Decision about Me, without Me, D.o. Health, Editor, Department of Health, London.

[112] White, R.O., Eden, S., Wallston, K.A., Kripalani, S., Barto, S., Shintani, A. and Rothman, R.L. (2015) Health Communication, Self-Care and Treatment Satisfaction among Low-Income Diabetes Patients in a Public Health Setting. Patient Education and Counseling, 98, 144-149. http://dx.doi.org/10.1016/j.pec.2014.10.019

[113] Emmons, K.M. and Rollnick, S. (2001) Motivational Interviewing in Health Care Settings Opportunities and Limitations. American Journal of Preventative Medicine, 20, 68-74. http://dx.doi.org/10.1016/S0749-3797(00)00254-3

[114] Vansteenkiste, M. and Ryan, R.M. (2013) On Psychological Growth and Vulnerability: Basic Psychological Need Satisfaction and Need Frustration as a Unifying Principle. Journal of Psychotherapy Integration, 23, 263-280. http://dx.doi.org/10.1037/a0032359

[115] Elwyn, G., Frosch, D., Thomson, R., Joseph-Williams, N., Lloyd, A., Kinnersley, P., et al. (2012) Shared Decision Making: A Model for Clinical Practice. Journal of General Internal Medicine, 27, 1361-1367. http://dx.doi.org/10.1007/s11606-012-2077-6

[116] Vaughn, S., Mauk, K.L., Jacelon, C.S., Larsen, P.D., Rye, J., Wintersgill, W. and Dufresne, D. (2015) The Competency Model for Professional Rehabilitation Nursing. Rehabilitation Nursing, 41, 33-44. http://dx.doi.org/10.1002/rnj.225

[117] Hibbard, J.H. and Greene, J. (2013) What the Evidence Shows about Patient Activation: Better Health Outcome and Care Experiences; Few Data on Costs. Health Affairs, 32, $207-$ 214. http://dx.doi.org/10.1377/hlthaff.2012.1061 
[118] Proot, I.M., Ter Meulen, R.H.J. and Abu-Saad, H.H. (2007) Supporting Stroke Patients' Autonomy during Rehabilitation. Nursing Ethics, 14, 229-241. http://dx.doi.org/10.1177/0969733007073705

[119] Eaton, S., Roberts, S. and Turner, B. (2015) Delivering Person Centred Care in Long Term Condition. British Medical Journal, 350, h181. http://dx.doi.org/10.1136/bmj.h181

[120] Bernabeo, E. and Holmboe, E.S. (2013) Patients, Providers, and Systems Need to Acquire a Specific Set of Competencies to Achieve Truly Patient-Centered Care. Health Affairs, 32, 250-258. http://dx.doi.org/10.1377/hlthaff.2012.1120

[121] Yamont, B., Issa, Z., Herlopian, A., El Bejjani, M., Khalifa, A., Ghadieh, A.S. and Habib, R.H. (2013) Predictors of Quality of Life among Multiple Sclerosis Patients: A Comprehensive Analysis. European Journal of Neurology, 20, 756-764. http://dx.doi.org/10.1111/ene.12046

[122] Hayter, A.L., Salkovskis, P.M., Silber, E. and Morris, R.G. (2016) The Impact of Health Anxeity in Patients with Relapsuing Remitting Multiple Sclerosis; Misperception, Misattirbution and Quality of Life. The British Journal of Clinical Psychology, 55, 371-386. http://dx.doi.org/10.1111/bjc.12106

[123] Simmons, R.D. (2010) Life Issues in Multiple Sclerosis. Nature Reviews in Neurology, 6, 603-610. http://dx.doi.org/10.1038/nrneurol.2010.143

[124] Soundy, A., Rosenbaum, S., Elder, T., Kyte, D., Stubbs, B., Hemmings, L., et al. (2016) Face and Content Validation of the Hope and Adaptation Scale (Has). International Journal of Therapy and Rehabiliation.

[125] Pawlikowska, T., Zhang, W., Griffiths, F., van Dalen, J. and van der Vleuten, C. (2012) Verbal and Non-Verbal Behavior of Doctors and Patients in Primary Care ConsultationsHow This Relates to Patient Enablement. Patient Education and Counseling, 86, 70-76. http://dx.doi.org/10.1016/j.pec.2011.04.019

[126] Collins, L.G., Schrimmer, A., Diamond, J. and Burke, J. (2011) Evaluating Verbal and NonVerbal Communication Skills in an Ethnogeriatric OSCE. Patient Education and Counseling, 83, 158-162. http://dx.doi.org/10.1016/j.pec.2010.05.012

[127] Department of Health (1999) Patient and Public Invovlement in the New NHS, Department of Health, Editor, Department of Health, London.

\section{Submit or recommend next manuscript to SCIRP and we will provide best service for you:}

Accepting pre-submission inquiries through Email, Facebook, LinkedIn, Twitter, etc.

A wide selection of journals (inclusive of 9 subjects, more than 200 journals)

Providing 24-hour high-quality service

User-friendly online submission system

Fair and swift peer-review system

Efficient typesetting and proofreading procedure

Display of the result of downloads and visits, as well as the number of cited articles

Maximum dissemination of your research work

Submit your manuscript at: http://papersubmission.scirp.org/

Or contact ojtr@scirp.org 